\title{
Accounting for potassium and magnesium in irrigation water quality assessment
}

\author{
by J.D. Oster, Garrison Sposito and Chris J. Smith
}

Irrigation with treated wastewater is expected to increase significantly in California during the coming decade as a way to reduce the impact of drought and mitigate water transfer issues. To ensure that such wastewater reuse does not result in unacceptable impacts on soil permeability, water quality guidelines must effectively address sodicity hazard. However, current guidelines are based on the sodium adsorption ratio (SAR) and thus assume that potassium $(K)$ and magnesium $(\mathrm{Mg})$, which often are at elevated concentrations in recycled wastewaters, pose no hazard, despite many past studies to the contrary. Recent research has established that the negative effects of high $K$ and Mg concentrations on soil permeability are substantial and that they can be accounted for by a new irrigation water quality parameter, the cation ratio of structural stability (CROSS), a generalization of SAR. We show that CROSS, when suitably optimized, correlates strongly with a standard measure of soil permeability reduction for an agricultural soil leached with winery wastewater, and that it can be incorporated directly into existing irrigation water quality guidelines by replacing SAR.

$\mathrm{R}$ ecycled wastewaters generated by municipalities and farms in California are being reused increasingly for irrigation, both to expand available water resources and to avoid discharge to surface waters, with the current statewide goal being to reuse 2.5 million acre-feet of wastewater by 2030
(Weber et al. 2014). However, the high salinity and sodium $(\mathrm{Na})$ concentrations characteristic of recycled wastewaters pose a significant challenge to their sustainable reuse for crop production (Assouline et al. 2015; Laurenson et al. 2012; Platts and Grismer 2014a, 2014b). Adding to this challenge, several recent studies (Arienzo et al. 2012; Buelow et al. 2015; Marchuk et al. 2013; Rengasamy and Marchuk 2011; Smith et al. 2015) have documented deleterious effects on soil hydraulic properties caused by high concentrations of potassium $(\mathrm{K})$ and magnesium $(\mathrm{Mg})$, which are typical of recycled wastewaters (Buelow et al. 2015; Laurenson et al. 2012; Weber et al. 2014). The potential consequences include negative impacts on infiltration, water availability and plant growth. Buelow et al. (2015), who investigated California soils, in particular have called for further research to understand the high-risk scenarios that may arise when irrigating with potassium-rich wastewaters. We note in passing that recycled wastewaters are not the only concern of the kind discussed here. High concentrations of $\mathrm{Mg}$ occur naturally in groundwater in and near the Coast Range in California because of their serpentine geology (Ben Faber and Mark Battany, UC ANR Cooperative Extension, personal communication, 2015).

All of the studies cited indicated that the negative impacts of $\mathrm{K}$ and $\mathrm{Mg}$ on the saturated soil hydraulic conductivity

Online: http://dx.doi.org/10.3733/ca.v070n02p71

High concentrations of potassium and

magnesium are typically found in recycled wastewaters and can have negative impacts on infiltration, water availability and plant growth 


\section{Development of water quality guidelines for irrigated agriculture in California}

$\mathrm{T}$ he quality of water for irrigated agriculture is based on the effect the water can have on crop growth and on soil permeability. The salt concentration in irrigation water is the primary factor that affects crop growth: water quality decreases as the salt concentration increases. Water quality impacts on soil permeability are more complicated. Two opposing factors need to be considered: salt concentration, as estimated conventionally by electrical conductivity (EC), and sodicity hazard, as reflected in the sodium adsorption ratio (SAR), which is calculated according to Equation (1) using the concentrations of $\mathrm{Na}$, $\mathrm{Ca}$ and $\mathrm{Mg}$ in the irrigation water. The effects of EC and SAR on soil permeability are opposite to one another: permeability increases with increasing EC, whereas permeability decreases with increasing SAR. Consequently, soil permeability is maintained by an optimal combination of high EC and low SAR. The irrigation water quality guidelines based on this optimization that are used to assess possible negative impacts on soil permeability (table 1) are those proposed by Ayers and Westcot (1985).

TABLE 1. Interpretive guidelines for assessing the combined effect of SAR and EC in irrigation water on soil infiltration problems

\begin{tabular}{clcc}
\hline \hline & \multicolumn{3}{c}{ Degree of impact of SAR according to EC } \\
\cline { 2 - 4 } SAR & None & \multicolumn{1}{c}{ Slight to moderate } & Severe \\
\hline$\left(\mathrm{mmol}_{\mathrm{c}} / \mathrm{L}\right)^{0.5}$ & $\ldots \ldots \ldots \ldots \ldots \ldots \ldots d S / m \ldots \ldots \ldots \ldots \ldots \ldots$ \\
$0-3$ & $>0.7$ & $0.7-0.2$ & $<0.2$ \\
$3-6$ & $>1.2$ & $1.2-0.3$ & $<0.3$ \\
$6-12$ & $>1.9$ & $1.9-0.5$ & $<0.5$ \\
$12-20$ & $>2.9$ & $2.9-1.3$ & $<1.3$ \\
$20-40$ & $>5.0$ & $5.0-2.9$ & $<2.9$
\end{tabular}

Source: Ayers and Westcot 1985. exchangeable sodium and the ratio of air permeat sodium percentage (ESP) and exchangeable potassium percentage (EPP). This ratio in creases exponentially with ESP, whereas for EPP there is no increase for three of the seven soils examined, while the increase is small for the other four. In parallel with this perspective concerning $\mathrm{K}$, Mg was considered to have positive effects equal to those of Ca on soil permeability, leading Handbook 60 to group the two bivalent cations together in promoting and maintaining good soil structure. Bresler et al. (1982) have noted, however, that this customary grouping in fact may not reflect the true status of $\mathrm{Mg}$, which, like $\mathrm{K}$, is typically masked by the two- to fivefold greater concentration of Ca over Mg in irrigation waters.

Interestingly, at about the same time that Handbook 60 was discounting $\mathrm{K}$ when assessing the impacts of irrigation water quality on soil permeability, it was becoming known that the negative impact on soil permeability of $\mathrm{K}$ was in fact not negligible and that the positive impacts of Ca and Mg on permeability were not equal. Quirk and Schofield (1955), inspired by research on the effects of salt concentration on the permeability of agricultural soils in California (Fireman and Bodman 1939), reported what appears to be the first systematic investigation to quantify the separate effects of $\mathrm{Na}, \mathrm{K}, \mathrm{Mg}$ and $\mathrm{Ca}$ on the saturated soil hydraulic conductivity. They equilibrated soil pads with concentrated $\mathrm{Cl}$ solutions of $\mathrm{Na}, \mathrm{K}, \mathrm{Ca}$ or $\mathrm{Mg}$, then leached the pads with a series of more dilute $\mathrm{Cl}$ solutions of the same cation. Their results showed decreases in the hydraulic conductivity over a 5-hour period of leaching which clearly depended on the type of cation. The magnitude of these decreases followed the order: $\mathrm{Na}>\mathrm{K}>\mathrm{Mg}>\mathrm{Ca}$. CA place them between the extremes of $\mathrm{Na}$ as the worst soil dispersant and calcium (Ca) as the best soil flocculant: $\mathrm{Na}>\mathrm{K}$ $>\mathrm{Mg}>\mathrm{Ca}$. In general, flocculation has a positive impact on soil permeability while dispersion has a negative impact. Although this ordering of negative impacts on soil hydraulic properties among the four cations was documented quantitatively 60 years ago (Quirk and Schofield 1955) and has often been discussed in reviews (Keren 1984; Levy 2012), it has not yet been incorporated into standard irrigation water quality criteria. As noted by Rengasamy and Marchuk (2011) and Buelow et al. (2015), the need to do this has become urgent because of increasing need to reuse wastewaters for irrigation, which is expected to grow exponentially in California during the next few decades (Weber et al. 2014).

In respect to the impacts of $\mathrm{Na}$ on soil permeability, the sodium adsorption ratio (SAR) has long been the standard diagnostic parameter for sodicity hazard (U.S. Salinity Laboratory Staff 1954):

$$
\mathrm{SAR}=\mathrm{Na} /[(\mathrm{Ca}+\mathrm{Mg}) / 2)]^{0.5}
$$

where each chemical element symbol indicates a concentration in millimoles of charge per liter $\left(\mathrm{mmol}_{\mathrm{c}} / \mathrm{L}\right)$. SAR can be related through rigorous thermodynamic arguments to the exchangeable sodium percentage (Oster and Sposito 1980), a key soil property impacting permeability (Bresler et al. 1982; Keren 1984; Levy 2012; Shainberg and Letey 1984). Similarly, a potassium adsorption ratio (PAR) has been defined with $\mathrm{K}$ concentration replacing that of $\mathrm{Na}$ (U.S. Salinity Laboratory Staff 1954); but, as noted above, there are as yet no guidelines based on PAR in standard reference publications related to irrigation water quality assessment (Ayers and Westcot 1985; Rhoades et al. 1992; Tanji and Kielen 2002; Tyagi and Minhas 1998; Wallender and Tanji 2012). (See sidebar, "Development of water quality guidelines for irrigated agriculture in California.")

\section{CROSS, a new irrigation water quality parameter}

Building on earlier conceptual work by Rengasamy and Sumner (1998), Rengasamy and Marchuk (2011) have proposed a generalization of SAR which quantifies both the differing effects of $\mathrm{Na}$ and $\mathrm{K}$ as dispersing cations diminishing 
soil permeability and the differing effects of $\mathrm{Mg}$ and $\mathrm{Ca}$ as flocculating cations enhancing soil permeability. This new parameter, the cation ratio of structural stability (CROSS), incorporates the inverse of the critical flocculation (or coagulation) concentration (Rengasamy and Sumner 1998; Sposito 2008) for a cation as a measure of its "relative flocculating power," which is taken as a chemical basis for distinguishing cations that promote soil particle aggregation from those that promote soil particle dispersion. Rengasamy and Sumner (1998) reported critical flocculation concentrations (CFCs) for Na-, $\mathrm{K}$-, Mg- and Ca-saturated clays extracted from four soils, which they then used to calculate the average relative flocculating power of each cation by dividing its average $\mathrm{CFC}$ for the four soils into the average CFC for Na-clay, taken as a reference. Compared to $\mathrm{Na}$, the average relative flocculating power of $\mathrm{K}, \mathrm{Mg}$ and $\mathrm{Ca}$ for the four soils was found to be $1.8 \pm 0.3,27 \pm 5$ and $45 \pm 8$, respectively. Thus a measure of the dispersing power of $\mathrm{K}$ relative to $\mathrm{Na}$ would be $1.0 / 1.8=0.56$ and a measure of the flocculating power of $\mathrm{Mg}$ relative to $\mathrm{Ca}$ would be $27 / 45=0.60$. Rengasamy and Marchuk (2011) then proposed the following generalization of SAR:

$$
\mathrm{CROSS}_{\mathrm{f}}=\frac{(\mathrm{Na}+0.56 \mathrm{~K})}{[(\mathrm{Ca}+0.60 \mathrm{Mg}) / 2]^{0.5}}
$$

where we have added a subscript $f$ to indicate that the two numerical coefficients in CROSS are based on the relative flocculating power of $\mathrm{K}$ and $\mathrm{Mg}$. Rengasamy and Marchuk (2011) tested CROSS $\mathrm{f}$ as a diagnostic water quality parameter by comparing it to SAR in obtaining high correlation with the percent dispersible clay in four Australian soils. Although SAR did correlate significantly with percent dispersible clay, the correlation with CROSS $_{\mathrm{f}}$ was greatly superior. Similarly, Marchuk and Rengasamy (2012) reported a highly significant linear correlation between $\mathrm{CROSS}_{\mathrm{f}}$ and the salt concentration (expressed conventionally as electrical conductivity) required to flocculate three Australian soils. They concluded that, by including the dispersive effects of $\mathrm{K}$ in addition to $\mathrm{Na}$ and differentiating the flocculating effects of $\mathrm{Mg}$ from $\mathrm{Ca}, \mathrm{CROSS}_{\mathrm{f}}$ performed better than SAR in predicting soil clay dispersion and flocculation.

\section{Optimizing CROSS}

Additional insight into the significance of CROSS can be had by generalizing Equation (2):

$$
\begin{aligned}
\mathrm{CROSS} & =(\mathrm{Na}+a \mathrm{~K}) /[(\mathrm{Ca}+b \mathrm{Mg}) / 2]^{0.5} \\
& =\mathrm{SAR}^{*}+a \mathrm{PAR}^{*}
\end{aligned}
$$

where $a$ and $b$ are numerical coefficients to be determined by a suitable method and

$$
\begin{aligned}
& \mathrm{SAR}^{*}=\mathrm{Na} /[(\mathrm{Ca}+b \mathrm{Mg}) / 2]^{0.5} \\
& \mathrm{PAR}^{*}=\mathrm{K} /[(\mathrm{Ca}+b \mathrm{Mg}) / 2]^{0.5}
\end{aligned}
$$

are generalizations of SAR and PAR, respectively. According to the ordering of negative cation impacts on soil permeability as determined by Quirk and Schofield (1955), $\mathrm{Na}>\mathrm{K}>\mathrm{Mg}>\mathrm{Ca}$. (See sidebar, "Why do cations with the same valence have different effects on soil permeability?") Therefore, the coefficients $a$ and $b$ in Equation (3) are both expected to have values $<1$, as they do in Equation (2). Equation (3) suggests further that CROSS can be interpreted as the weighted sum of a generalized SAR and PAR, with the weighting factor $a<1$ interpreted as a measure of the lesser negative impact of $\mathrm{PAR}^{*}$ on soil permeability relative to SAR* The coefficient $b<$ 1 can be interpreted as a multiplier of the actual concentration of $\mathrm{Mg}$ to produce an "effective concentration" of Mg. This smaller effective concentration reflects the lower flocculating power of $\mathrm{Mg}$ relative to Ca. Evidently the concentration of $\mathrm{Mg}$ in an irrigation water would have to be $1 / b$ times larger than that of Ca so as to have the same positive impact as Ca on soil permeability. Since $b<1$, SAR $<$ SAR $^{*}$ and PAR $<$ PAR $^{*}$, which implies that CROSS $\geq S A R$ for any water composition. Therefore, the use of CROSS as a diagnostic tool to evaluate irrigation water quality according to standard criteria (Ayers and Westcot 1985) will result in a more conservative assessment of potential soil management problems. (See sidebar, "Using CROSS to assess irrigation water quality.")

In their seminal study of cation effects on soil permeability, Quirk and Schofield (1955) defined the cation concentration low enough to result in a $10 \%$ to $15 \%$ reduction in the saturated hydraulic conductivity, after leaching with water of known composition for a prescribed time-period, as the

\section{Why do cations with the same valence have different effects on soil permeability?}

$T^{T}$ he phenomenon underlying the validity of either SAR or CROSS is soil particle flocculation caused by cation adsorption (Sposito 2008). Diffuse double layer theory (Rengasamy and Sumner 1998; Sposito 2008), which often is used to model cation adsorption leading to flocculation, hypothesizes that only cation valence matters in flocculation. Hence all cations of a given valence should adsorb to soil particles and flocculate them in the same way, although monovalent cations should be less effective than bivalent cations. This is the basis for the definition and chemical validity of SAR (Oster and Sposito 1980).

However, as noted by Rengasamy and Sumner (1998), if cations with the same valence adsorb with differing strength to soil particles, this will affect flocculation. Recently, Marchuk and Rengasamy (2011) defined a molecular-scale geochemical parameter for estimating the relative strength of cation adsorption, the ionicity index. This parameter reflects specific cation effects in adsorption by quantifying the relative tendency of a cation to adsorb weakly to soil particles; higher ionicity index implies weaker adsorption. (The opposite of ionicity is covalency, which results in strong adsorption to soil particles.) They showed that the ordering of the ionicity index among the four common cations in irrigation waters is $\mathrm{Na}(0.891)>\mathrm{K}(0.863)>\mathrm{Mg}(0.735)>\mathrm{Ca}(0.670)$, thus increasing from weakest to strongest adsorption, and that this index is highly correlated with the dispersion (as conventionally measured by turbidity) of both reference clay and soil clay suspensions. The ionicity index goes beyond diffuse double layer theory by saying that both valence and the relative strength of cation adsorption to soil particles influences the flocculating power of a cation. Following this line of reasoning, we suggest that the differences among Na, K, Mg and Ca reflected by the numerical coefficients in CROSS are related to the ionicity index of the cations. CA 
threshold concentration (TEC). The TEC is a widely adopted, convenient measure of the impact of cations on soil permeability (Buelow et al. 2015; Quirk 2001; Shainberg and Letey 1984). Accordingly, we tested Equation (3) as a diagnostic water quality parameter by examining how well it correlates with TEC values we calculated (table 4) using laboratory data reported by Jayawardane et al. (2011) and Arienzo et al. (2012) for a Sodosol from the Riverina region of Australia which had been irrigated with winery wastewater (Smith et al. 2015). Like many irrigated California soils, this soil is high (>50\%) in smectite clay minerals and has alkaline $\mathrm{pH}(>8)$, with a surface horizon of clay loam texture overlying a subsurface horizon of medium clay texture.

A linear correlation between $\mathrm{CROSS}_{\mathrm{f}}$ in Equation (2) and the TEC values in table

\section{Using CROSS to assess irrigation water quality}

$C_{i c}^{a n}$ urrently, CROSS is the only tested irrigation water quality parameter that accounts for the effects of all four major cations on soil physical properties. It is based on the premise that the effects of $\mathrm{K}$ and $\mathrm{Mg}$ on the permeability of soils, at threshold levels of EC, are due to the dispersion of soil aggregates and consequent blockage of soil pores. The same relationships hold for the effects of $\mathrm{Na}$ and $\mathrm{Ca}$. Consequently incorporating $\mathrm{K}$ and $\mathrm{Mg}$ does not pose new deleterious mechanisms for consideration, and the use of CROSS as a diagnostic tool should be similar to the use of SAR. Published research dating back at least 60 years documents the negative impacts of $\mathrm{K}$ and $\mathrm{Mg}$ on physical properties of soils and clays from Australia, Kazakhstan, South Africa, Niger, the United States and the United Kingdom (Aylmore and Sills 1982; Dontsova and Norton 2002; Horn 1983; Levy and van der Watt 1990; Quirk and Schofield 1955; Reeve et al. 1954; Rengasamy and Sumner 1998; Vyshpolsky et al. 2010; Zhang and Norton 2002). In most cases, the soils studied contained substantial amounts of illite and smectite, typical clay minerals in irrigated soils in California (Buelow et al. 2015).

The interpretative guidelines for irrigation water quality involving SAR and CROSS should therefore be similar. Also, the same procedures to adjust the $\mathrm{Ca}$ concentration for effects of bicarbonate on calcite precipitation leading to SAR adj (Ayers and Westcot 1985; Lesch and Suarez 2009) can be used to calculate an adjusted value of CROSS. Values of CROSS opt calculated with Equation (6) for 10 waters applied in California — five municipal wastewaters, two river waters, and three canal waters - are given in table 2. As noted in connection with Equation (3), CROSS > SAR in all cases. For two of the wastewaters, and one river water, the predicted impact of the water on soil permeability increased from none to slight to moderate using $\mathrm{CROSS}_{\text {opt }}$ instead of SAR (table 3). This more conservative assessment is an expected effect of including all four major cations with their differing impacts on soil permeability when evaluating irrigation water quality. CA

TABLE 2. Water quality assessment of irrigation waters and wastewaters used for irrigation in California

\begin{tabular}{|c|c|c|c|c|c|c|c|c|c|c|}
\hline \multirow[b]{2}{*}{ Water source } & \multirow[b]{2}{*}{$\mathrm{Ca}$} & \multirow{2}{*}{$\begin{array}{c}\mathrm{Ca} \\
\mathrm{adj}^{*}\end{array}$} & \multirow[b]{2}{*}{$\mathrm{Mg}$} & \multirow[b]{2}{*}{$\mathrm{Na}$} & \multirow[b]{2}{*}{ K } & \multirow[b]{2}{*}{ EC } & SAR & CROSS $_{\text {opt }}$ & SAR & CROSS $_{\mathrm{opt}}$ \\
\hline & & & & & & & \multicolumn{2}{|c|}{ Using Ca } & \multicolumn{2}{|c|}{ Using $\mathrm{Ca}$ adj } \\
\hline & $\ldots \ldots$ & ....... & $\mathrm{mol}_{\mathrm{c}}$ & $\ldots \ldots$ & $\ldots \ldots$ & $d S / m$ & & $\cdots \cdots(m m c$ & LL) $)^{0.5}$. & 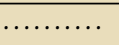 \\
\hline Sacramento River & 0.6 & 1.1 & 0.6 & 0.5 & 0.30 & 0.18 & 0.6 & 1.1 & 0.5 & 0.8 \\
\hline Gage Canal & 2.9 & 2.0 & 0.7 & 1.5 & 0.00 & 0.50 & 1.1 & 1.2 & 1.3 & 1.5 \\
\hline $\begin{array}{l}\text { California } \\
\text { Aqueduct }\end{array}$ & 1.7 & 2.0 & 1.2 & 3.4 & 0.10 & 0.68 & 2.8 & 3.6 & 2.7 & 3.4 \\
\hline $\begin{array}{l}\text { Delta-Mendota } \\
\text { Canal }\end{array}$ & 2.8 & 4.0 & 0.8 & 3.5 & 0.00 & 0.69 & 2.6 & 2.9 & 2.3 & 2.5 \\
\hline Colorado River & 4.6 & 2.6 & 2.9 & 9.5 & 0.10 & 1.48 & 4.9 & 6.1 & 5.7 & 8.0 \\
\hline Fresno wastewater & 1.3 & 1.0 & 1.1 & 3.4 & 0.40 & 0.69 & 3.1 & 4.2 & 3.3 & 4.8 \\
\hline $\begin{array}{l}\text { Santa Rosa } \\
\text { wastewater }\end{array}$ & 2.0 & 1.6 & 1.6 & 3.9 & 0.30 & 0.70 & 2.9 & 3.9 & 3.1 & 4.3 \\
\hline $\begin{array}{l}\text { Bakersfield } \\
\text { wastewater }\end{array}$ & 2.3 & 1.6 & 0.4 & 4.7 & 0.70 & 0.88 & 4.0 & 4.6 & 4.7 & 5.5 \\
\hline $\begin{array}{l}\text { South Bay } \\
\text { wastewater }\end{array}$ & 2.6 & 2.0 & 2.5 & 6.4 & 0.40 & 1.21 & 4.0 & 5.5 & 4.3 & 6.2 \\
\hline $\begin{array}{l}\text { Palo Alto } \\
\text { wastewater }\end{array}$ & 2.3 & 3.0 & 2.8 & 8.5 & 0.00 & 1.35 & 5.3 & 7.6 & 5.0 & 6.7 \\
\hline
\end{tabular}

*Ca adj calculated using Table 11 in Ayers and Westcot (1985), which contains Ca adj values calculated as proposed by Suarez (1981).

TABLE 3. Irrigation water quality assessment (degree of impact on soil permeability) based on the guidelines in table 1 and the data in table 2

\begin{tabular}{lccccc}
\hline & \multicolumn{3}{c}{ Water quality assessment } \\
\cline { 2 - 5 } Water source & \multicolumn{2}{c}{ Ca } & \multicolumn{2}{c}{ Ca adj } \\
\cline { 2 - 5 } \cline { 2 - 5 } Sacramento River & SAR & CROSS & SAR & CROSS \\
Gage Canal & Severe & Severe & Severe & Severe \\
California Aqueduct & SM* & SM & SM & SM \\
Delta-Mendota Canal & SM & SM & SM & SM \\
Colorado River & SM & SM & SM & SM \\
Fresno wastewater & None & SM & None & SM \\
Santa Rosa wastewater & SM & SM & SM & SM \\
Bakersfield wastewater & SM & SM & SM & SM \\
South Bay wastewater & SM & SM & SM & SM \\
Palo Alto wastewater & None & None & None & SM \\
\hline
\end{tabular}

${ }^{*} \mathrm{SM}=$ slight to moderate. 
4 is shown in figure $1 \mathrm{~A}$. This correlation is good enough to confirm the hypothesis that negative soil permeability effects of $\mathrm{K}$ and $\mathrm{Mg}$ are important. Figure $1 \mathrm{~B}$ shows the much-improved linear correlation between the generalized CROSS in Equation (3) and TEC that we obtained using an optimization technique to provide best-fit values of the coefficients $a$ and $b$ (Duan et

TABLE 4. Sodium (SAR) and potassium adsorption ratio (PAR), threshold concentration (TEC) and cation concentrations in applied water leading to a $15 \%$ reduction in the saturated hydraulic conductivity of surface and subsurface layers in a calcareous soil from the Riverina region of Australia

\begin{tabular}{|c|c|c|c|c|c|c|}
\hline Soil layer & SAR or PAR* & TEC & K & $\mathrm{Na}$ & $\mathrm{Mg}$ & $\mathrm{Ca}$ \\
\hline & & \multicolumn{5}{|c|}{ 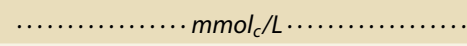 } \\
\hline Surface & SAR40 Ca & 66.0 & 0.00 & 61.30 & 0.00 & 4.70 \\
\hline Surface & PAR40 Ca & 15.5 & 15.21 & 0.00 & 0.00 & 0.29 \\
\hline Surface & SAR20 Ca & 30.2 & 0.00 & 26.70 & 0.00 & 3.50 \\
\hline Surface & PAR20 Ca & 9.6 & 9.18 & 0.00 & 0.00 & 0.42 \\
\hline Surface & SAR5 Ca & 2.0 & 0.00 & 1.76 & 0.00 & 0.24 \\
\hline Surface & PAR5 Ca & 2.0 & 1.76 & 0.00 & 0.00 & 0.24 \\
\hline Subsurface & SAR40 Ca & 134.0 & 0.00 & 116.90 & 0.00 & 17.10 \\
\hline Subsurface & PAR40 Ca & 32.9 & 31.65 & 0.00 & 0.00 & 1.25 \\
\hline Subsurface & SAR20 Ca & 16.7 & 0.00 & 15.50 & 0.00 & 1.20 \\
\hline Subsurface & PAR20 Ca & 26.9 & 24.92 & 0.00 & 0.00 & 1.98 \\
\hline Subsurface & SAR5 Ca & 1.5 & 0.00 & 1.35 & 0.00 & 0.15 \\
\hline Subsurface & PAR5 Ca & 1.5 & 1.35 & 0.00 & 0.00 & 0.15 \\
\hline Surface & $\mathrm{SAR} 40 \mathrm{Ca}+\mathrm{Mg}$ & 191.0 & 0.00 & 159.30 & 15.85 & 15.85 \\
\hline Surface & PAR40 Ca+ Mg & 22.6 & 22.00 & 0.00 & 0.30 & 0.30 \\
\hline Surface & SAR20 Ca+Mg & 66.9 & 0.00 & 52.95 & 6.98 & 6.98 \\
\hline Surface & PAR20 Ca+Mg & 10.7 & 10.18 & 0.00 & 0.26 & 0.26 \\
\hline Surface & SAR5 $\mathrm{Ca}+\mathrm{Mg}$ & 1.5 & 0.00 & 1.35 & 0.07 & 0.07 \\
\hline Surface & PAR5 $\mathrm{Ca}+\mathrm{Mg}$ & 2.0 & 1.76 & 0.00 & 0.12 & 0.12 \\
\hline Subsurface & $\mathrm{SAR} 40 \mathrm{Ca}+\mathrm{Mg}$ & 224.8 & 0.00 & 183.00 & 20.90 & 20.90 \\
\hline Subsurface & PAR40 Ca+ Mg & 71.9 & 66.40 & 0.00 & 2.75 & 2.75 \\
\hline Subsurface & $\mathrm{SAR} 20 \mathrm{Ca}+\mathrm{Mg}$ & 33.3 & 0.00 & 29.10 & 2.10 & 2.10 \\
\hline Subsurface & $\mathrm{PAR} 20 \mathrm{Ca}+\mathrm{Mg}$ & 7.1 & 6.87 & 0.00 & 0.12 & 0.12 \\
\hline Subsurface & SAR5 $\mathrm{Ca}+\mathrm{Mg}$ & 1.0 & 0.00 & 0.93 & 0.03 & 0.03 \\
\hline Subsurface & PAR5 $\mathrm{Ca}+\mathrm{Mg}$ & 1.0 & 0.93 & 0.00 & 0.03 & 0.03 \\
\hline Surface & SAR40 Mg & 517.0 & 0.00 & 357.00 & 160.00 & 0.00 \\
\hline Surface & PAR40 Mg & 140.0 & 121.50 & 0.00 & 18.50 & 0.00 \\
\hline Surface & SAR20 Mg & 283.0 & 0.00 & 158.00 & 125.00 & 0.00 \\
\hline Surface & PAR20 Mg & 99.5 & 73.00 & 0.00 & 26.50 & 0.00 \\
\hline Surface & SAR5 Mg & 23.2 & 0.00 & 12.00 & 11.20 & 0.00 \\
\hline Surface & PAR5 Mg & 18.9 & 10.30 & 0.00 & 8.60 & 0.00 \\
\hline Subsurface & SAR40 Mg & 501.0 & 0.00 & 349.00 & 152.00 & 0.00 \\
\hline Subsurface & PAR40 Mg & 136.0 & 118.50 & 0.00 & 17.50 & 0.00 \\
\hline Subsurface & SAR20 Mg & 156.0 & 0.00 & 103.00 & 53.00 & 0.00 \\
\hline Subsurface & PAR20 Mg & 60.7 & 49.00 & 0.00 & 11.70 & 0.00 \\
\hline Subsurface & SAR5 Mg & 8.7 & 0.00 & 5.90 & 2.80 & 0.00 \\
\hline Subsurface & PAR5 Mg & 15.1 & 8.85 & 0.00 & 6.25 & 0.00 \\
\hline
\end{tabular}

Source: Arienzo et al. 2012.

*The number is the corresponding SAR, or PAR, for the cation concentrations within the same row. CROSS is: al. 1993; Rosenbrock 1960). The optimized

$$
\begin{aligned}
\text { CROSS }_{\text {opt }} & =\text { SAR }^{*}+0.335( \pm 0.038) \mathrm{PAR}^{*} \\
& =\frac{(\mathrm{Na}+0.335( \pm 0.038) \mathrm{K})}{(\mathrm{Ca}+0.0758( \pm 0.012) \mathrm{Mg}) / 2)^{0.5}}
\end{aligned}
$$

where "opt" designates optimization. Comparison of figure $1 \mathrm{~A}$ with figure $1 \mathrm{~B}$ shows that use of Equation (6) instead of Equation (2) improves the correlation of CROSS with TEC dramatically.

The optimized values of the coefficients $a$ and $b$ in Equation (6) can be interpreted chemically as follows. The electrolyte concentration required to cause flocculation of soil clays is usually considerably greater than that which results in the dispersion of soil clays (Quirk 2001). In light of this fact, the TEC values for $\mathrm{Na}$ and $\mathrm{K}$ reported by Quirk and Schofield (1955), which relate to soil clay dispersion, might be better suited to estimate the $a$ coefficient in CROSS than the CFC values Rengasamy and Marchuk (2011) used. Under this hypothesis, the value for $a$ should equal the ratio of TEC for $\mathrm{K}(67$ $\left.\mathrm{mmol}_{\mathrm{c}} / \mathrm{L}\right)$ to that for $\mathrm{Na}\left(250 \mathrm{mmol}_{\mathrm{C}} / \mathrm{L}\right)$ as determined by Quirk and Schofield (1955), which is 0.27 . The optimized value of $a$ in
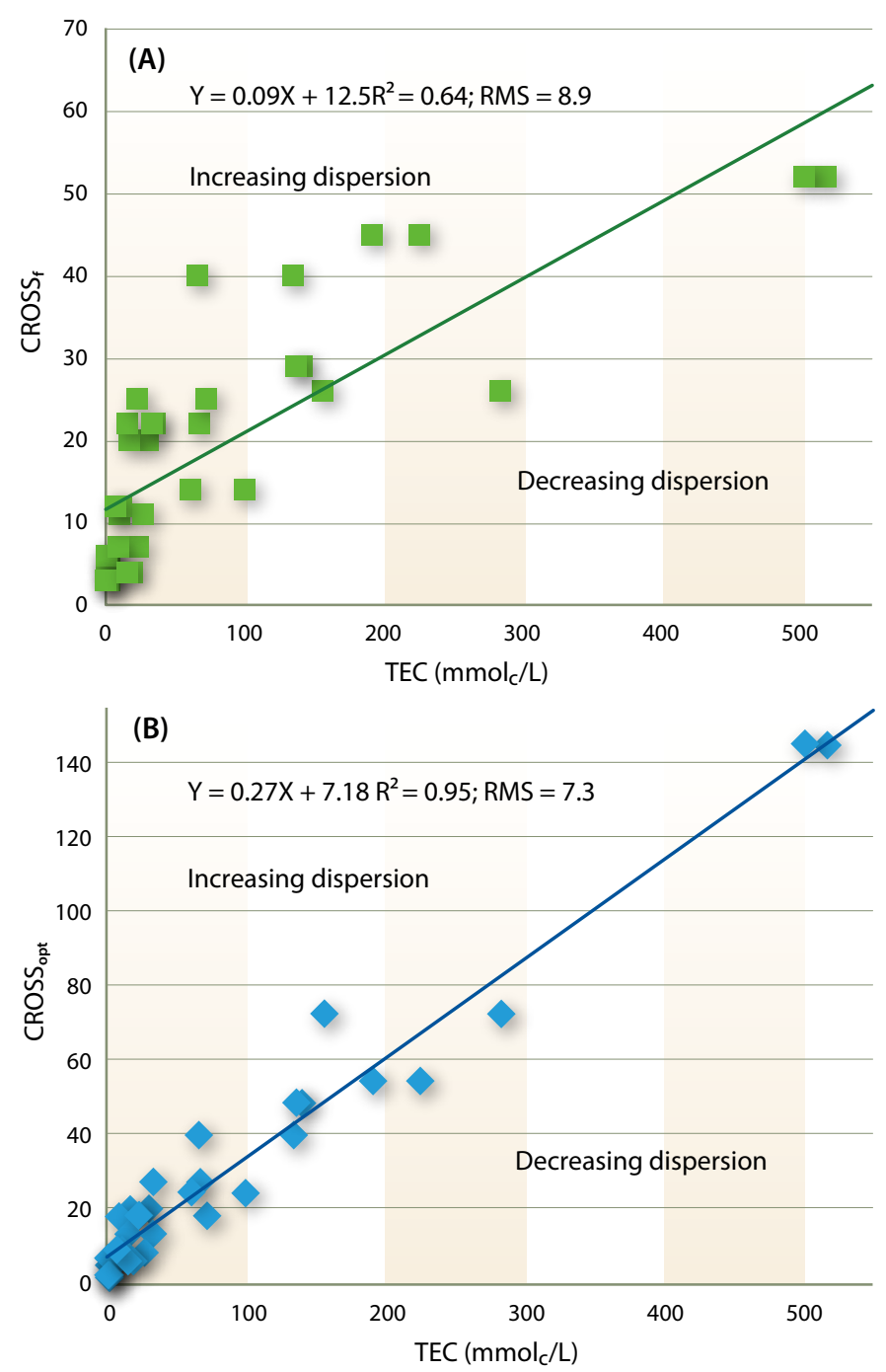

Fig. 1. Correlations between the cation ratio of structural stability (CROSS), with the coefficients for $\mathrm{K}$ and $\mathrm{Mg}$ based on their $(\mathrm{A})$ relative flocculating power $\left(\mathrm{CROSS}_{\mathrm{f}}\right)$ or (B) statistically optimized (CROSS $\left.{ }_{\text {opt }}\right)$, and the threshold concentration $\left(\mathrm{TEC}, \mathrm{mmol}_{\mathrm{C}} / \mathrm{L}\right.$ ) in applied water leading to a $15 \%$ reduction in the relative saturated hydraulic conductivity of a calcareous soil from the Riverina region of Australia (Arienzo et al. 2012). RMS represents the rootmean-square. 
Equation (6), which indicates the dispersive power of $K$ to be about one-third that of $\mathrm{Na}$, is consistent with this estimate.

Our optimized $b$ coefficient, however, is not approximately equal to $a$, as it is in Equation (2). Following the discussion given above, its very small value implies that the concentration of $\mathrm{Mg}$ needs to be about an order of magnitude larger than that of $\mathrm{Ca}$ in order to have the same positive effect as $\mathrm{Ca}$ in promoting soil flocculation. This large difference can, in fact, be deduced from directly examining the data in table 4 . For example, the TEC values associated with SAR40 Ca and SAR40 $\mathrm{Mg}$ are 66.0 and $517.0 \mathrm{mmol}_{\mathrm{c}} / \mathrm{L}$, respectively. Here the coefficient $a$ plays no role; the coefficient $b$ (and, therefore, $\mathrm{Mg}$ ) is solely responsible for the second, much larger value of TEC. According to Equation (6), CROSS $_{\text {opt }}$ for TEC $=517$ $\mathrm{mmol}_{\mathrm{c}} / \mathrm{L}$ is equal to 147 . In this case $\mathrm{CROSS}_{\text {opt }}$ is equal to SAR*. Since SAR = 40, SAR $^{*}$ is 3.67 times larger than SAR, implying $b=0.0743$, which agrees with the optimized value.

\section{Conclusions}

Sixty years of research on soil permeability as affected by irrigation water quality have established that the decreasing order of negative impacts of the four major cations follows the sequence: $\mathrm{Na}$ $>\mathrm{K}>\mathrm{Mg}>\mathrm{Ca}$. Current irrigation water quality guidelines (Ayers and Westcot 1985) omit K entirely and consider $\mathrm{Mg}$ to have no negative impacts on soil hydraulic properties. The new irrigation water quality parameter, CROSS (Rengasamy and Marchuk 2011), a generalization of SAR, accounts for the negative impacts of $\mathrm{K}$ and $\mathrm{Mg}$ on soil permeability. We found an excellent correlation between a suitably optimized CROSS and TEC, a standard measure of the reduction in soil permeability under leaching, for a Sodosol irrigated with winery wastewater having significant concentrations of $\mathrm{K}$ and $\mathrm{Mg}$ (fig. 1B). Thus we propose the substitution of CROSS for SAR in irrigation water quality guidelines as a generalization of sodicity hazard to include the relative deleterious impact on soil hydraulic properties of the four common cations. CA

J.D. Oster is Emeritus Specialist, Department of Environmental Sciences, UC Riverside; G. Sposito is Chancellor's Professor, Emeritus, Department of Environmental Science, Policy and Management, UC Berkeley; C.J. Smith is Fellow, CSIRO Agriculture, Canberra, Australia.

Support for Dr. Smith was provided by the Australian Water Recycling Centre of Excellence and the CSIRO Water for a Healthy Country Research Flagship, and Dr. Sposito was supported in part by an appointment as Chancellor's Professor, Emeritus, administered through the College of Natural Resources, UC Berkeley.

We thank California Agriculture Associate Editor Dr. K. Bali and two reviewers for their helpful comments on a draft version of this paper, as well as Nat Dellavalle, whose comments to Dr. J.D. Oster about permeability problems of a soil caused by high levels of $K$ was the "spark" that initiated our work with CROSS.

\section{References}

Aylmore LAG, Sills JD. 1982. Characterization of soi structure and stability using modulus of ruptureexchangeable sodium percentage relationships. Aust Soil Res 20:213-24.

Arienzo M, Christen EW, Jayawardane NS, Quayle WC. 2012. The relative effects of sodium and potassium on soil hydraulic conductivity and implications for winery wastewater management. Geoderma 173-174:303-10.

Assouline S, Russo D, Silber A, Or D. 2015. Balancing water scarcity and quality for sustainable irrigated agriculture. Water Resour Res 51:3419-36.

Ayers RS, Westcot DW. 1985 Water quality for agriculture FAO Irrig. Drain. Pap. 29, Rev.1. Rome, Italy: FAO.

Bresler E, McNeal BL, Carter DL. 1982. Saline and Sodic Soils. Springer-Verlag. Berlin, Germany.

Buelow MC, Steenwerth K, Parikh SJ. 2015. The effect of mineral-ion interactions on soil hydraulic conductivity. Agr Water Manage 152:277-85

Dontsova KM, Norton LD. 2002. Clay dispersion, infiltration and erosion as influenced by exchangeable $\mathrm{Ca}$ and Mg. Soil Sci 167:184-93.

Duan QY, Gupta VK, Sorooshian S. 1993. Shuffled complex evolution approach for effective and efficient globa minimization. J Optimiz Theory Appl 76(3):501-21. Fireman M, Bodman GB. 1939. The effect of saline irrigation water upon the permeability and base status of soils Soil Sci Soc Am Proc 4:71-7.

Jayawardane NS, Christen EW, Arienzo M, Quayle WC 2011. Evaluation of the effects of cation combinations on soil hydraulic conductivity. Soil Res 49: 56-64.

Horn CP. 1983. The effect of cations on soil structure. Dip. Agr. Sci. Thesis. University of New England, Armidale, Australia.

Keren R. 1984. Potassium, magnesium, and boron in soils under saline and sodic conditions. In: Shainberg L, Shalhevet J (eds.). Soil Salinity under Irrigation: Processes and Management. Berlin, Germany: Springer-Verlag. p. 77-99.

Laurenson S, Bolan NS, Smith E, McCarthy M. 2012. Use of recycled wastewater. Aust J Grape and Wine Res 18:1-10.
Lesch SM, Suarez DL. 2009. A short note on calculating the adjusted SAR index. Amer Soc Agric Eng 52(2):493-6.

Levy GJ. 2012. Sodicity. In: Huang PM, Li Y, Sumner ME (eds.). Handbook of Soil Sciences (2nd ed.). Resource Management and Environmental Impacts. Boca Ratón, FL: CRC Press. Chap. 18

Levy GJ, van der Watt HvH. 1990. Effect of exchangeable potassium on the hydraulic conductvity and infiltration rate of some South African soils. Soil Sci 149:69-77.

Marchuk A, Rengasamy P, McNeill A, Kumar A. 2013. Nature of the clay-cation bond affects soil structure as verified by X-ray computed tomography. Soil Res 50: 638-44. Oster JD, Sposito G. 1980. The Gapon coefficient and the exchangeable sodium percentage-sodium adsorption ratio relation. Soil Sci Soc Am J 44: 258-60.

Platts BE, Grismer ME. 2014a. Chloride levels increase after 13 years of recycled water use in the Salinas Valley. Calif Agr 68(3):68-74

Platts BE, Grismer ME. 2014b. Rainfall leaching is critical for long-term use of recycled water in Salinas Valley. Calif Agr 68(3):75-81.

Quirk JP. 2001. The significance of the threshold and turbidity concentrations in relation to sodicity and microstructure. Aust J Soil Res 39:1185-1217.

Quirk JP, Schofield RK. 1955. The effect of electrolyte concentration on soil permeability. J Soil Sci 6:163-78.

Reeve RC, Bower CA, Brooks RH, Gwchwend FB. 1954. A comparison of the effects of exchangeable sodium and potassium upon the physical condition of soils. Soil Sci Soc Am Proc 18:130-2.

Rengasamy P, Sumner ME. 1998. Processes involved in sodic behaviour. In: Sumner ME, Naidu R (eds.). Sodic Soil: Distribution, Properties, Management and Environmental Consequences. New York: Oxford University Press. p. $35-50$

Rengasamy P, Marchuk A. 2011. Cation ratio of soils structural stability (CROSS). Soil Res 49:280-5.

Rhoades JD, Kandiah A, Mashali AM. 1992. The use of saline waters for crop production. FAO Irrig. Drain. Pap. 48. Rome, Italy: FAO.
Rosenbrock HH. 1960. An automatic method for finding the greatest or least value of a function. Computer $\mathrm{J} 3$ : 175-84.

Shainberg I, Letey J. 1984. Response of soils to sodic and saline conditions. Hilgardia 52(2):1-57.

Smith CJ, Oster JD, Sposito G. 2015. Potassium and magnesium in irrigation water quality assessment. Agr Water Manage 157:59-64

Sposito G. 2008. The Chemistry of Soils ( $2^{\text {nd }}$ ed.). New York: Oxford University Press

Suarez DL. 1981. Relation between pHc and Sodium Adsorption Ratio (SAR) and an alternate method of estimating SAR of soil or drainage waters. Soil Sci Soc Amer J 45:469-75.

Tanji KK, Kielen NC. 2002. Agricultural drainage water management in arid and semi-arid areas. FAO Irr. Drain. Pap. 61. Rome, Italy: FAO.

Tyagi NK, Minhas PS. 1998. Agricultural salinity management in India. Karnal, India: Soil Salinity Research Institute.

U.S. Salinity Laboratory Staff. 1954. Diagnosis and Improvement of Saline and Alkali Soils. Handbook No. 60 Washington, DC: USDA.

Vyshpolsky F, Mukhamedjanov K, Bekbaev U, et al. 2010. Optimizing the rate and timing of phosphogypsum application to magnesium-affected soils for crop yield and water productivity enhancement. Agric Water Manage 97:1277-86.

Wallender WW, Tanji KK. 2012. Agricultural Salinity Assessment and Management. ASCE Manuals and Reports on Engineering Practice No. 71. Reston, VA: American Society of Civil Engineers.

Weber E, Grattan SR, Hanson BR, et al. 2014. Recycled water causes no salinity or toxicity issues in Napa vineyards. Calif Agr 68(3):59-67.

Zhang XC, Norton, LD. 2002. Effect of exchangeable Mg on saturated hydraulic conductivity, disaggregation and clay dispersion of disturbed soils. J Hydrol 26:194-205. 